\title{
Electrophysiological effects of trace amines on mesencephalic dopaminergic neurons
}

\section{Ada Ledonne 1,2, Nicola Berretta ${ }^{2}$, Alessandro Davoli1,2, Giada Ricciardo Rizzo 1,2, Giorgio Bernardi1,2 and Nicola Biagio Mercuri ${ }^{1,2 *}$}

\author{
" Università degli Studi di Roma "Tor Vergata," Rome, Italy \\ 2 Experimental Neurology Laboratory, Istituto Di Ricovero e Cura a Carattere Scientifico Fondazione Santa Lucia, Rome, Italy
}

\section{Edited by:}

Elizabeth Abercrombie,

Rutgers-Newark The State University

of New Jersey, USA

\section{Reviewed by:}

KueiY.Tseng, Rosalind Franklin

University of Medicine and Science,

USA

James M. Tepper, Rutgers, The State

University of New Jersey, USA

*Correspondence:

Nicola Biagio Mercuri, Centro Europeo Ricerca sul Cervello, Via del Fosso di

Fiorano 64 00143, Rome, Italy.

e-mail:mercurin@med.uniroma2.it
Trace amines (TAs) are a class of endogenous compounds strictly related to classic monoamine neurotransmitters with regard to their structure, metabolism, and tissue distribution. Although the presence of TAs in mammalian brain has been recognized for decades, until recently they were considered to be by-products of amino acid metabolism or as "false" neurotransmitters. The discovery in 2001 of a new family of G-protein-coupled receptors (GPCRs), namely trace amines receptors, has re-ignited interest inTAs. In particular, two members of the family, trace amine receptor $1\left(T A_{1}\right)$ and trace amine receptor $2\left(T_{2}\right)$, were shown to be highly sensitive to these endogenous compounds. Experimental evidence suggests thatTAs modulate the activity of catecholaminergic neurons and that TA dysregulation may contribute to neuropsychiatric disorders, including schizophrenia, attention deficit hyperactivity disorder, depression and Parkinson's disease, all of which are characterized by altered monoaminergic networks. Here we review recent data concerning the electrophysiological effects of TAs on the activity of mesencephalic dopaminergic neurons. In the context of recent data obtained with TA, receptor knockout mice, we also discuss the mechanisms by which the activation of these receptors modulates the activity of these neurons. Three important new aspects of TAs action have recently emerged: (a) inhibition of firing due to increased release of dopamine; (b) reduction of D2 and GABA receptor-mediated inhibitory responses (excitatory effects due to disinhibition); and (c) a directTA, receptor-mediated activation of GIRK channels which produce cell membrane hyperpolarization. While the first two effects have been well documented in our laboratory, the direct activation of GIRK channels by TA, receptors has been reported by others, but has not been seen in our laboratory (Geracitano et al., 2004). Further research is needed to address this point, and to further characterize the mechanism of action of TAs on dopaminergic neurons.

Keywords: dopaminergic neurons, tyramine, $\beta$-phenylethylamine, trace amine receptor 1 , neuropsychiatric disorders
Trace amines (TAs) are a class of endogenous compounds strictly related to classic monoaminergic neurotransmitters, regarding the structure, metabolic pathways, cellular localization, and tissue distribution (Berry, 2004; Grandy, 2007). The group includes $\beta$-phenylethylamine ( $\beta$-PEA), tyramine (TYR), octopamine (OCT), synephrine (SYN), and tryptamine (TRP). TAs have been identified in several prokaryotic and eukaryotic organisms and in all investigated vertebrate and invertebrate species, including humans (Grandy, 2007). Their distribution in the mammalian brain strictly corresponds to the location of the main monoaminergic nuclei and their projecting areas.

Trace amines and biogenic amines share the same biosynthetic and metabolic pathways (Figure 1). They are produced in monoaminergic neurons from aromatic amino acids L-phenylalanine and tyrosine by amino acid decarboxylase (AADC), and are mainly catabolized by monoamine oxidase (MAO). Although the rates of synthesis are similar, TAs levels in the brain are two orders of magnitude lower than of classic monoaminergic neurotransmitters, most likely due to a rapid turnover, with a half-life of approximately $30 \mathrm{~s}$. Although synaptosomal localization of TAs has been reported (Baldessarini and Vogt, 1972; Boulton and Baker,
1975), the evidence for the existence of specific mechanisms for vesicular storage is still controversial. Recently, both vesicular and non-vesicular release of TAs has been described (Kosa et al., 2000; Grandy, 2007). Due to their highly lipophilic nature (particularly of $\beta$-PEA) it is possible that TAs are mainly released from axon terminals by diffusion across the cell membrane, and that their levels reflect an equilibrium between synthesis and catabolism (Berry, 2004).

In invertebrates, TAs act as neurotransmitters to control a variety of physiological functions, including locomotion, feeding, and learning-associated behaviors (Roeder, 2005; Sotnikova et al., 2008). In contrast, in the mammalian brain the physiological role and the mechanisms of action of TAs remain poorly understood. They have been often regarded as by-products of amino acid metabolism with no clear functional relevance. TAs have also been considered to act as "false" neurotransmitters, due to their ability to release catecholamines in amphetamine-like manner, via their displacement from synaptic vesicles and a reversal of plasma membrane transporters. It could be possible that by emptying synaptic vesicles (but with no affinity to monoaminergic receptors), TAs could produce, in the long run, a weakening of monoaminergic transmission. 


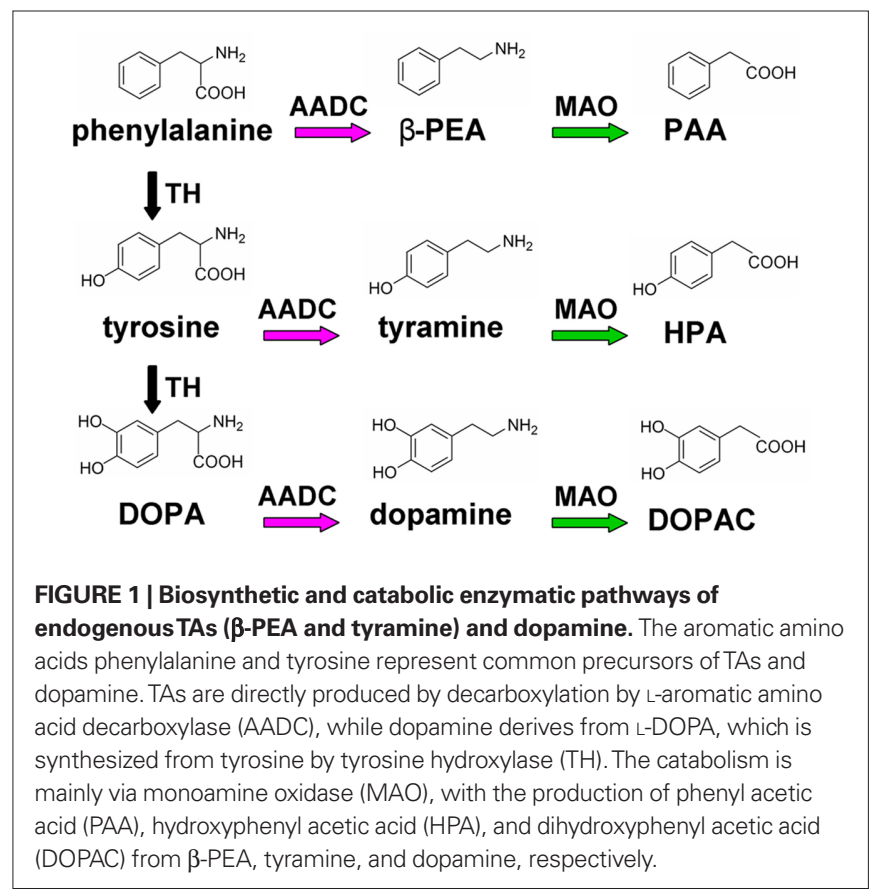

Recently, altered brain TAs levels have been reported in several neuropsychiatric disorders, including schizophrenia, attention deficit hyperactivity disorder (ADHD), depression, and Parkinson's disease (PD), suggesting the involvement of these amines in pathophysiology of monoaminergic systems (Branchek and Blackburn, 2003; Burchett and Hicks, 2006).

Interest in TAs has been re-ignited following the discovery, in 2001, of a novel class of G-protein-coupled receptors (GPCRs) that can be activated by these amines (Borowsky et al., 2001; Bunzow et al., 2001). The family of these "trace amine-associated receptors" (TAARs) consists of 15 members. However, only two, "trace amine receptor 1" $\left(\mathrm{TA}_{1}\right)$ and "trace amine receptor 2" $\left(\mathrm{TA}_{2}\right)$ (Maguire et al., 2009) were shown to be sensitive to TAs. TA, the best characterized receptor subtype, is coupled to $\mathrm{G}_{\mathrm{s}}$ protein and exerts its intracellular effect by activation of the adenylyl cyclase (Borowsky et al., 2001; Bunzow et al., 2001).

Trace amine receptor 1 receptors are distributed in the CNS mainly in the monoaminergic systems, including mesencephalic dopaminergic (DAergic) neurons, where they are co-localized with dopamine (DA) transporter, DAT (Xie et al., 2007). However, the physiological role of TA, receptors in the CNS in general, and in mesencephalic DAergic neurons in particular, is still not known. Recent studies suggest that these receptors modulate monoaminergic transmission (Sotnikova et al., 2008; Xie and Miller, 2009) by acting on monoamine transporters (e.g., DAT) and/or by directly affecting neuronal firing (Lindemann et al., 2008; Bradaia et al., 2009; Revel et al., 2011)

In addition to the $\mathrm{TA}_{1}$ receptor-mediated effects, other cellular mechanisms by which TAs affect the activity of monoaminergic neurons have been described. It has been reported that TAs can activate sigma $(\sigma)$ receptors which inhibit $\mathrm{K}^{+}$and $\mathrm{Ca}^{2+}$ ion channels (Nguyen et al., 1998; Zhang and Cuevas, 2002). In addition, in invertebrates TAs activate ligand-gated chloride channels (Pirri et al., 2009; Ringstad et al., 2009), suggesting that these endogenous compounds may modulate neuronal activity by triggering rapid ionic events also in vertebrates (Branicky and Schafer, 2009).

The first electrophysiological investigation of the effects of TAs on DAergic neuronal activity was an extracellular study conducted in midbrain slices by Pinnock (1983). He demonstrated an inhibitory effect of TYR and OCT on firing of DAergic neurons in the Substantia nigra pars compacta (SNpc). A similar inhibitory effect was demonstrated for $\beta$-PEA in extracellular recordings conducted from the same group of neurons in vivo (Rodriguez and Barroso, 1995). Intravenous applications of this amine $(0.4-3.4 \mathrm{mg} / \mathrm{kg})$ evoked a rapid but short-lasting (2-4 $\mathrm{min}$ ) reduction in the firing frequency and in the occurrence of bursting.

Trace amines-induced inhibitory effect on firing of SNpc DAergic neurons has been further characterized in our laboratory (Geracitano et al., 2004). Using intracellular recordings with sharp microelectrodes in rat midbrain slices, we have demonstrated that TAs reduce the spontaneous firing rate of these neurons in a reversible and concentration-dependent manner (Figure 2A). The inhibitory effect was mediated by indirect activation of somatodendritic D2 autoreceptors (D2 receptors located on DAergic neurons), consequent to increased DA release (Figure 2B). In particular, TAsinduced efflux of newly synthesized DA from reserpine-insensitive pools, through a mechanism involving both the membrane transporter-dependent and -independent mechanisms (Geracitano et al., 2004). More recent electrophysiological data demonstrated that TYR releases DA and indirectly activates D2 receptors also in subthalamic neurons (Zhu et al., 2007).

Trace amines can also modulate the activity of DAergic mesencephalic neurons by a direct action on $\mathrm{TA}_{1}$ receptors. Patch-clamp recordings of ventral tegmental area (VTA) DAergic neurons in mice with a knockout of $\mathrm{TA}_{1}$ receptors ( $\mathrm{TA}_{1} \mathrm{KO}$ mice) have demonstrated that these neurons have a higher spontaneous firing rate than in wild-type littermates (Lindemann et al., 2008; Bradaia et al., 2009). The increased firing rate of VTA neurons in TA $\mathrm{KO}$ mice supports the contention that, under normal conditions, there is a tonic inhibitory effect of TAs on DAergic neuron activity exerted through $\mathrm{TA}_{1}$ receptors. The inhibitory effect of TYR was not present in $\mathrm{TA}_{1} \mathrm{KO}$ mice, further indicating that the slower firing in wild-type animals is mediated by constitutive activation of TA 1 receptors by TAs (Lindemann et al., 2008). This was confirmed by using a selective TA receptor antagonist, $N$-(3-Ethoxyphenyl)-4-pyrrolidin-1-yl-3-trifluoromethyl-benzamide (EPPTB) that increased firing frequency of DAergic neurons in the VTA of wild-type mice, but not in TA $\mathrm{KO}$ mice (Bradaia et al., 2009). The latter study also demonstrated that TYR inhibits firing of these neurons by activation of $\mathrm{TA}_{1}$ receptors linked to G-protein-gated inwardly rectifying $\mathrm{K}^{+}$channels (GIRK channels; also known as Kir3) and additional experiments performed with heterologously expressed receptor and channel proteins in Xenopus oocytes showed that the $\mathrm{TA}_{1}$-induced GIRK channel activation involves a PTX-insensitive, G-protein-dependent mechanism (most likely Gs; Bradaia et al., 2009).

Trace amines modify neuronal responses to classic neurotransmitters, and thus exert neuromodulatory effects. Electrophysiological recordings conducted in our laboratory with sharp microelectrodes from SNpc DAergic neurons in midbrain slices revealed 
A

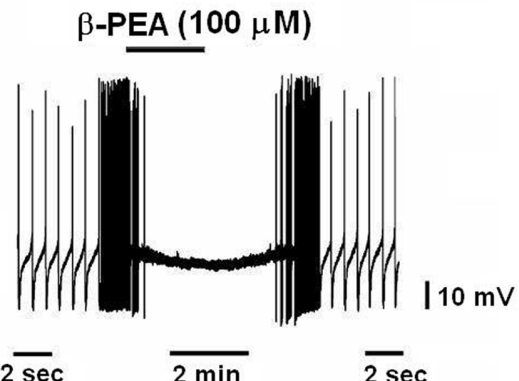

C

$\mathrm{GABA}_{B}-$ mediated IPSPS

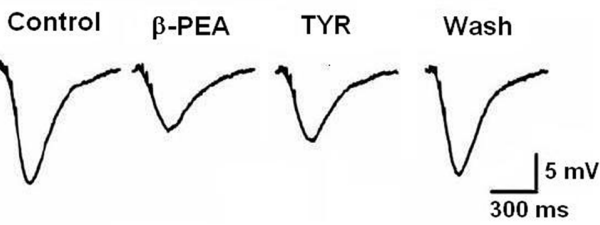

E

D2-activated GIRK currents

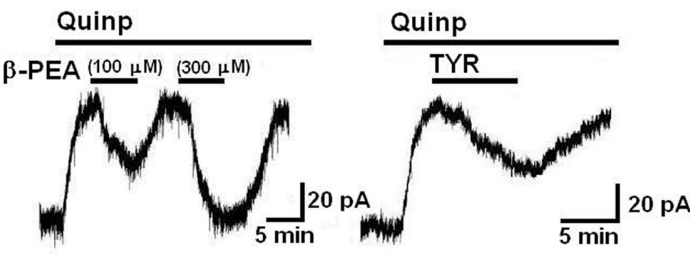

B

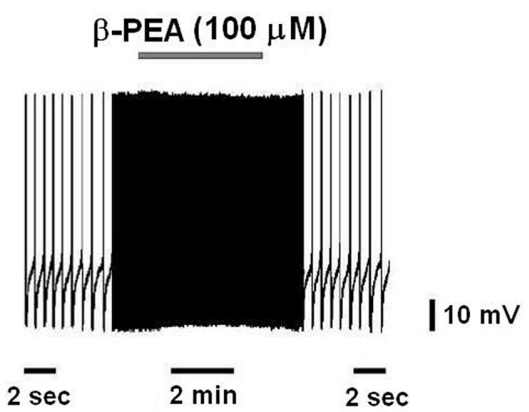

D

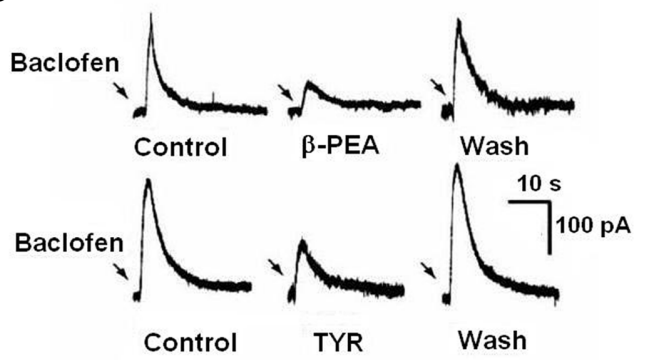

$\mathbf{F}$

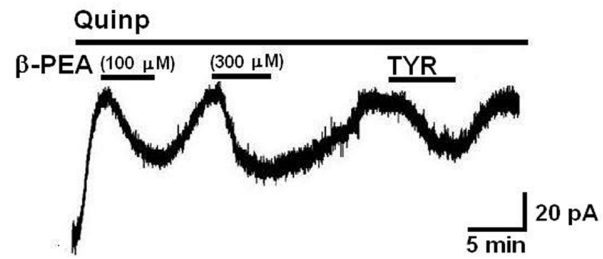

FIGURE 2 | Electrophysiological effects of TAs on mesencephalic dopaminergic neurons. (A) $\beta$-PEA produces a reversible hyperpolarization and inhibition of spontaneous firing in mesencephalic dopaminergic neurons. (B) The TAs-induced inhibition of firing is mediated by indirect activation of D2 autoreceptors, subsequent to the release of newly synthesized dopamine. The effect was absent in dopaminergic neurons treated with an inhibitor of DA synthesis (carbidopa, $300 \mu \mathrm{M}$ for $30 \mathrm{~min}$ ) and was blocked by a D2 receptor antagonist, sulpiride (1 $\mu \mathrm{M}$; data not shown). (C) The amplitude of electrically evoked inhibitory postsynaptic potentials (IPSPs) mediated by that TAs reduce GABAergic inhibitory neurotransmission to these neurons (Federici et al., 2005). In particular, both $\beta$-PEA and TYR, in micromolar concentrations, depressed the amplitude of electrically evoked inhibitory postsynaptic potentials (IPSPs) mediated by $\mathrm{GABA}_{\mathrm{B}}$ receptors (Figure $2 \mathrm{C}$ ), without modifying the $\mathrm{GABA}_{\mathrm{A}}-$ evoked synaptic responses (Federici et al., 2005). Moreover, the cellular responses (hyperpolarization/outward current) evoked by the stimulation of postsynaptic $\mathrm{GABA}_{\mathrm{B}}$ receptors with a $\mathrm{GABA}_{\mathrm{B}}$ agonist baclofen were reduced by both $\beta$-PEA and TYR (Figure 2D). The TAs-induced depression of $\mathrm{GABA}_{\mathrm{B}}$-mediated outward currents (involving GIRK channels) was neither dependent on protein kinases activity, nor on changes in the intracellular $\mathrm{Ca}^{2+}$ levels (Federici et al., 2005).
GABA $_{B}$ receptors is reduced by bath application of $\beta$-PEA $(100 \mu \mathrm{M})$ and TYR $(100 \mu \mathrm{M})$. (D) TAs reduce the outward currents produced by pressure application of the $\mathrm{GABA}_{\mathrm{B}}$ agonist, baclofen (arrows) in a reversible manner. (E) Negative modulatory effects of TAs on the D2-autoreceptors-mediated responses. The quinpirole-induced GIRK channel activation is reduced by both $\beta$-PEA and TYR in a reversible and concentration-dependent manner. (F) The D2/GIRK-mediated outward current evoked by TAs is not mediated by the activation of $T A_{1}$ receptors, since it was present in $T A_{1}$ receptor knockout mice.

Trace amines also reduce $\mathrm{GABA}_{\mathrm{B}}$-mediated responses at the presynaptic level. It is known that the inhibitory synaptic input to midbrain DAergic neurons mediated by GABA involves not only activation of postsynaptic $\mathrm{GABA}_{\mathrm{A}}$ receptors, but also presynaptic $\mathrm{GABA}_{\mathrm{B}}$ receptors which reduce GABA release (Giustizieri et al., 2005). We have reported that both $\beta$-PEA and TYR antagonize the $\mathrm{GABA}_{\mathrm{B}}$-dependent presynaptic inhibition of GABAergic inputs to SNpc DAergic neurons, by limiting the inhibitory effect of baclofen on the frequency of the spontaneous inhibitory postsynaptic currents $\left(\mathrm{GABA}_{\mathrm{A}}\right.$-induced sIPSCs; Berretta et al., 2005).

In addition, TAs have a neuromodulatory effect on the postsynaptic responses mediated by D2 receptors in DAergic neurons. Using conventional intracellular and single-electrode voltage-clamp 
recordings from SNpc DAergic neurons, we have demonstrated that cell membrane hyperpolarization/outward current induced by quinpirole (a D2 receptor agonist) is reduced by concomitant application of $\beta$-PEA and TYR (Ledonne et al., 2010). The effect was reversible and concentration-dependent (Figure 2E). In an attempt to characterize the mechanisms underlying the inhibition of quinpirole-induced responses, we found that TAs effects were not mediated by $\mathrm{TA}_{1}$ (Figure $2 \mathrm{~F}$ ) and sigma $(\sigma)$ receptors, nor were dependent on G-protein activation. Furthermore, inhibitory effects of TAs on D2 receptor-mediated responses could not be demonstrated in Xenopus oocytes expressing both D2 receptors and GIRK channel (Ledonne et al., 2010). The latter results suggest that the inhibitory effect of TAs on DAergic neurons depends on the activation of not yet identified neuron-specific sites.

All these results indicate that TAs control the activity of DAergic mesencephalic neurons through a complex mechanism that involves both indirect and direct inhibitory effects. Indirect effects are due to DA release through a reversal of DAT function, and possibly by a non-DAT-mediated mechanism. This causes an strengthening of DAergic inhibition mediated by somatodendritic D2 receptors (Geracitano et al., 2004). Direct inhibitory effects depend on activation of TA 1 receptors. The results obtained by others in $\mathrm{TA}_{1} \mathrm{KO}$ mice and using specific antagonists of these receptors indicated that TAs tonically inhibit the activity of DAergic VTA neurons (Bradaia et al., 2009; Revel et al., 2011). However, we could not see a direct inhibitory effect of TA in SNpc and VTA neurons in our experiments. A part the technical differences in recording the dopaminergic cells (intracellular versus patch-clamp) we do not have a suitable explanation to account for the discrepancy between these and our results.

\section{REFERENCES}

Baldessarini, R. J., and Vogt, M. (1972). Regional release of aromatic amines from tissues of the rat brain in vitro. J. Neurochem. 19, 755-761.

Berretta, N., Giustizieri, M., Bernardi, G., and Mercuri, N. B. (2005). Trace amines reduce $\mathrm{GABAB}$ receptormediated presynaptic inhibition at GABAergic synapses of the rat substantia nigra pars compacta. Brain Res. 1062, 175-178.

Berry, M. D. (2004). Mammalian central nervous system trace amines. Pharmacological amphetamines, physiological neuromodulators. $J$. Neurochem. 90, 257-271.

Borowsky, B., Adham, N., Jones, K. A., Raddatz, R.,Artymyshyn, R., Ogozalek, K. L. Durkin, M. M., Lakhlani, P. P., Bonini, J. A., Pathirana, S., Boyle, N., $\mathrm{Pu}, \mathrm{X}$., Kouranova, E., Lichtblau, H., Ochoa, F. Y., Branchek, T. A., and Gerald, C. (2001). Trace amines: identification of a family of mammalian G protein-coupled receptors. Proc. Natl. Acad. Sci. U.S.A. 98, 8966-8971.

Boulton, A. A., and Baker, G. B. (1975). The subcellular distribution of $\beta$-phenylethylamine, $\mathrm{p}$-tyramine and tryptamine in rat brain. J. Neurochem. $25,477-481$.
Bradaia, A., Trube, G., Stalder, H., Norcross, R. D., Ozmen, L., Wettstein, J. G., Pinard, A., Buchy, D., Gassmann, M., Hoener, M. C., and Bettler, B. (2009). The selective antagonist EPPTB reveals TAAR1-mediated regulatory mechanisms in dopaminergic neurons of the mesolimbic system. Proc. Natl. Acad. Sci. U.S.A. 106, 20081-20086.

Branchek, T. A., and Blackburn, T. P. (2003). Trace amines receptors as target for novel therapeutics: legend, myth and fact. Curr. Opin. Pharmacol. 3, 90-97.

Branicky, R., and Schafer, W. R. (2009). Tyramine: a new receptor and a new role at the synapse. Neuron 62 , 458-460.

Bunzow, J. R., Sonders, M. S., Arttamangkul, S., Harrison, L. M., Zhang, G., and Quigley, D. I., Darland, T., Suchland, K. L., Pasumamula, S., Kennedy, J. L., Olson, S. B., Magenis, R. E., Amara, S. G., and Grandy, D. K. (2001). Amphetamine, 3,4-methylenedioxymethamphetamine, lysergic acid diethylamide, and metabolites of the catecholamine neurotransmitters are agonists of a rat trace amine receptor. Mol. Pharmacol. 60, 1181-1188.

On the other hand, the inhibitory effect of TAs of both $\mathrm{GABA}_{\mathrm{B}}$ and D2-mediated GIRK currents (Federici et al., 2005; Ledonne et al., 2010) can increase the excitability of VTA and SNpc neurons. Neuronal excitability can be also affected by receptor-mediated presynaptic effects (Berretta et al., 2005). A still unresolved issue is the functional role of $\mathrm{TA}_{1}$ receptors. The electrophysiological data obtained so far suggest a complex action in which the inhibitory effects of TAs mediated by DA release and increased GABAergic input (due to a reduction of the $\mathrm{GABA}_{\mathrm{B}}$ receptor-mediated control of GABA release) could prevail over the excitation (due to disinhibition resulting from reduced inhibitory effects of DA and GABA). However, it could be also possible that in some physiological and/ or pathological situations the excitatory effect of TAs prevail over their inhibitory action.

Further studies are needed to define the functional role of TAs and $\mathrm{TA}_{1}$ receptors in DAergic neurons. More attention should be also given to the question of how TAs affect the DA-mediated postsynaptic effects and synaptic plasticity in VTA/SNpc neurons and their targets (e.g., in the striatum and nucleus accumbens; cf., Calabresi et al., 2007; Kreitzer and Malenka, 2008). Pending on these investigations, TAs and TA receptors could be considered as potential therapeutic targets in psychiatric and neurodegenerative disorders involving a dysfunction of DAergic system, such as schizophrenia, ADHD, depression, dyskinesia, and PD.

\section{ACKNOWLEDGMENT}

The authors are grateful to Dr. Janusz Lipsky for the advices in correcting and modifying the manuscript.

Burchett, S. A., and Hicks, T. P. (2006). The mysterious trace amines: protean neuromodulators of synaptic transmission in mammalian brain. Prog Neurobiol. 79, 223-246.

Calabresi, P., Picconi, B., Tozzi, A., and Di Filippo, M. (2007). Dopaminemediated regulation of corticostriatal synaptic plasticity. Trends Neurosci. 30, 211-219.

Federici, M., Geracitano, R., Tozzi, A., Longone, P., Di Angelantonio, S. Bengston, C. P., Bernardi, G., and Mercuri, N. B. (2005). Trace amines depress $\mathrm{GABA}_{\mathrm{B}}$ response in dopaminergic neurons by inhibiting $G \beta \gamma$-gated inwardly rectifying potassium channels. Mol. Pharmacol. 67, 1283-1290.

Geracitano, R., Federici, M., Prisco, S. Bernardi, G., and Mercuri, N. B. (2004). Inhibitory effects of trace amines on rat midbrain dopaminergic neurons. Neuropharmacology 46 807-814.

Giustizieri, M., Bernardi, G., Mercuri, N. B., and Berretta, N. (2005). Distinct mechanisms of presynaptic inhibition at GABAergic synapses of the rat substantia nigra pars compacta. $J$. Neurophysiol. 94, 1992-2003.

Grandy, D. K. (2007). Trace amineassociated receptor 1-Family arche- type or iconoclast? Pharmacol. Ther. $116,355-390$

Kosa, E., Marcilhac-Flouriot, A., Fache, M. P., and Siaud, P. (2000). Effects of beta phenylethylamine on the hypothalamo-pituitary-adrenal axis in the male rat. Pharmacol. Biochem. Behav. 67, 527-535.

Kreitzer,A. C., and Malenka, R. C. (2008). Striatal plasticity and basal ganglia circuit function. Neuron 60, 543-554.

Ledonne, A., Federici, M., Giustizieri, M., Pessia, M., Imbrici, P., Millan, M. J., Bernardi, G., and Mercuri, N. B. (2010). Trace amines depress D2-autoreceptor-mediated responses on midbrain dopaminergic cells. Br. J. Pharmacol. 160, 1509-1520.

Lindemann, L., Meyer, C. A., Jeanneau, K., Bradaia, A., Ozmen, L., Bluethmann, H., Bettler, B., Wettstein, J. G., Borroni, E., Moreau, J. L., and Hoener, M. C. (2008). Trace amine-associated receptor 1 modulates dopaminergic activity. J. Pharmacol. Exp. Ther. 324, 948-956. Maguire, J. J., Parker, W. A., Foord, S. M., Bonner, T. A., Neubig, R. R., and Davenport, A. P. (2009). International Union of Pharmacology. LXXII. Recommendations for trace amine receptor nomenclature. Pharmacol. Rev. 61, 1-8. 
Nguyen, V. H., Ingram, S. L., Kassiou, M., and Christie, M. J. (1998). $\sigma$-Binding sites ligands inhibit $\mathrm{K}^{+}$currents in rat locus coeruleus neurons in vitro. Eur. J. Pharmacol. 361, 157-163.

Pinnock, R. D. (1983). Sensitivity of compacta neurones in the rat substantia nigra slice to dopamine agonists. Eur. J. Pharmacol. 96, 269-276.

Pirri, J. K., McPherson, A. D., Donnelly, J. M., Francis, M. M., and Alkema, M. J. (2009). A tyramine-gated chloride channel coordinates distinct motor programs of a Caenorhabditis elegans escape response. Neuron 62, 526-538.

Revel, F. G., Moreau, J. L., Gainetdinov, R. R., Bradaia, A., Sotnikova, T. D., Mory, R., Durkin, S., Zbinden, K. G., Norcross, R., Meyer, C. A., Metzler, V., Chaboz, S., Ozmen, L., Trube, G., Pouzet, B., Bettler, B., Caron, M. G., Wettstein, J. G., and Hoener, M. C. (2011). TAAR1 activation modulates monoaminergic neurotransmission, preventing hyperdopaminergic and hypoglutamatergic activity. Proc. Natl. Acad. Sci. U.S.A. 108, 8485-8490.

Ringstad, N., Abe, N., and Horvitz, R. (2009). Ligand gated chloride channels are receptors for biogenic amines in C. elegans. Science 325, 96-100.

Rodriguez, M., and Barroso, N. (1995). $\beta$-Phenylethylamine regulation of dopaminergic nigrostriatal cell activity. Brain Res. 703, 201-204.

Roeder, T. (2005). Tyramine and octopamine: ruling behaviour and metabolism. Annu. Rev. Entomol. 50, 447-477.

Sotnikova, T. D., Zorina, O. I., Ghisi, V., Caron, M. G., and Gainetdinov, R. R. (2008). Trace amine associated receptor 1 and movement control. Parkinsonism. Relat. Disord. 14, 99-102.

Xie, Z., and Miller, G. M. (2009). Trace amine-associated receptor 1 as a monoaminergic modulator in brain. Biochem. Pharmacol. 78, 1095-1104.

Xie, Z., Westmoreland, S. V., Bahn, M. E., Chen, G., Yang, H., Vallender, E. Yao, W. D., Madras, B. K., and Miller, G. M. (2007). Rhesus monkey trace amine-associated receptor 1 signalling: enhancement by monoamine transporters and attenuation by D2 autoreceptor in vitro. J. Pharmacol. Exp. Ther. 321, 116-127.

Zhang, H., and Cuevas, J. (2002). Sigma receptors inhibit high-voltage activated calcium channels in rat sympathetic and parasympathetic neurons. J. Neurophysiol. 87, 2867-2879.

Zhu, Z. T., Munhall, A. C., and Johnson, S. W. (2007). Tyramine excites rat subthalamic neurons in vitro by a dopamine-dependent mechanism. Neuropharmacology 52, 1169-1178.

Conflict of Interest Statement: The authors declare that the research was conducted in the absence of any commercial or financial relationships that could be construed as a potential conflict of interest.

Received: 31 January 2011; paper pending published: 27 March 2011; accepted: 16 June 2011; published online: 04 July 2011.

Citation: Ledonne A, Berretta N, Davoli A, Rizzo GR, Bernardi G and Mercuri NB (2011) Electrophysiological effects of trace amines on mesencephalic dopaminergic neurons. Front. Syst. Neurosci. 5:56. doi: 10.3389/fnsys.2011.00056

Copyright (c) 2011 Ledonne, Berretta, Davoli, Rizzo, Bernardi and Mercuri. This is an open-access article subject to a nonexclusive license between the authors and Frontiers Media SA, which permits use, distribution and reproduction in other forums, provided the original authors and source are credited and other Frontiers conditions are complied with. 